\title{
Changes of lymphocyte membrane fluidity in rheumatoid arthritis: a fluorescence polarisation study
}

\author{
E BECCERICA,${ }^{1}$ G PIERGIACOMI,${ }^{1}$ G CURATOLA,${ }^{2}$ AND G FERRETTI ${ }^{2}$ \\ From the Institutes of ${ }^{\prime}$ Rheumatology and ${ }^{2}$ Biochemistry, Medical Faculty, University of Ancona, Via \\ Ranieri, 60131 Ancona, Italy
}

SUMMARY Fluorescence polarisation of 1,6-diphenyl-1,3,5-hexatriene was used to study the lymphocyte membrane in rheumatoid arthritis. The increase of polarisation value in the patients $N$ $(n=27)$ compared with healthy controls $(n=32)$ suggests a decrease of membrane fluidity. 은 Moreover, erythrocyte sedimentation rate (ESR) and plasma fibrinogen concentrations $\overrightarrow{\breve{C}}$ were positively correlated with lymphocyte fluorescence polarisation values $(r=0.66$ and $r=0.76 \stackrel{5}{5}$ respectively). The results suggest that the changes in lymphocyte membrane fluidity could be involved in the pathogenetic mechanism of rheumatoid arthritis.

Key words: 1,6-diphenyl-1,3,5-hexatriene fluorescence polarisation.

Rheumatoid arthritis (RA) is characterised by complex abnormalities of the immunological system and by the presence of defects in the regulation of the immune response. The principal immunopathogenetic features are the production of rheumatoid factor, the presence of circulating immune complexes, and alterations in the functional activities of polymorphonuclear cells ${ }^{12}$ and lymphocytes. ${ }^{3-5}$ Immunoregulation is mediated by a complex network of cellular interactions involving both cellcell contacts and soluble factors. ${ }^{6}$ In these events a key role is performed by cell membranes, both plasmatic and intracellular, as they are involved in cellular recognition phenomena and in signal transduction. ${ }^{8}$ Although the aetiology of RA is still unknown, it has become evident that lymphocytes have an important role in the pathogenesis of RA, ${ }^{9}$ as suggested by the observation that profound clinical improvements follow depletion of recirculating lymphocytes either by lymphopheresis or thoracic duct drainage, ${ }^{10} 11$ and that lymphocyte reinfusion causes transient exacerbations. ${ }^{4}$ Several studies have shown abnormal lymphoid cell morphology $y^{12}$ and functions in the peripheral blood of patients with $\mathrm{RA}^{3-513}$ and an increase of circulating activated lymphocytes. ${ }^{14} 15$

Accepted for publication 25 November 1987.

Correspondence to Professor G Curatola, Istituto di Biochimica, Facoltà di Medicina e Chirurgia, Università degli Studi di Ancona, Via Ranieri, 60131 Ancona, Italia.
As cell membranes have been shown to be primarily involved in immune responses ${ }^{16}$ in in- $\mathbb{Q}$ flammatory and cytotoxic events, ${ }^{16}{ }^{17}$ the possibility $\overrightarrow{\vec{O}}$ of lymphocyte membrane alterations at the molecu- $\exists$ lar level has to be considered. Alterations in the $\supset$ behaviour of lymphocytes from patients with RA? may be due to abnormalities in membrane fluidity. Membrane fluidity has an important role in regulating cellular functions affecting the conformation of membrane-bound enzymes, ${ }^{18}$ the diffusion ${ }^{19}$ or the degree of receptor protein exposure, or both, and 0 their recycling ${ }^{20}$; fluidity as measured by spectrosco-

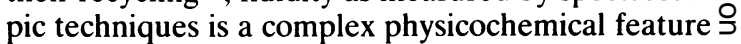
in which mobility and order of membrane compo- $\frac{7}{0}$ nents and membrane permeability properties are strictly interconnected. ${ }^{21}$ Changes in composition of and in molecular organisation are the principal determinants of alterations of membrane fluidity $\underset{\mathrm{N}}{\mathrm{N}}$ observed in many human diseases. ${ }^{22-27}$

In this study we used the fluorescence polarisation of 1,6-diphenyl-1,3,5-hexatriene (DPH), which hase been widely used to analyse membrane fluidity of $\Phi$ blood cells in normal and pathological condi-? tions. $^{23-27}$ The lipophilic probe DPH, though $\frac{0}{\circ}$ primarily embedded in the plasma membrane, is not $\frac{\overrightarrow{\mathbb{D}}}{\mathrm{D}}$ located exclusively there, but also penetrates the $\frac{\rho}{\mathbb{Q}}$

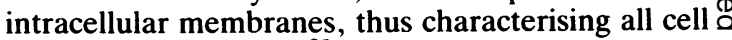
membrane apparatus. ${ }^{28}$

Our principal aim was to study the physicochemi- $\varnothing$ cal state of the lymphocyte membrane in patients? 
with RA and to try to correlate this with clinical and biochemical indices of RA activity. The results are discussed in the light of the possible involvement of lymphocyte membrane in the pathogenetic mechanism of RA.

\section{Patients and methods}

\section{PAT I ENTS}

Twenty seven patients ( 19 women, eight men; mean age 53.8 (SD 14.4) years, range 20-79) with classical or definite RA according to the criteria of the American Rheumatism Association were studied. None had taken disease modifying antirheumatic drugs for at least six months and nonsteroidal anti-inflammatory drugs for at least three days. Disease activity was assessed clinically by the Ritchie index and by measurement of a series of objective indices, including erythrocyte sedimentation rate (ESR), ${ }^{29} \alpha_{2}$ globulins, ${ }^{30} \mathrm{C}$ reactive protein (CRP), ${ }^{31}$ plasma fibrinogen concentrations, ${ }^{32}$ platelet count, plasma sulphydryl groups, ${ }^{33}$ and plasma viscosity. ${ }^{34}$

Thirty two healthy subjects ( 19 women, 13 men; mean age $45(15.4)$ years, range 22-78) acted as controls.

\section{LYM PHOCYTES}

Lymphocytes were obtained from freshly drawn heparinised blood by Ficoll-Isopaque (Lymphoprep; Nyegard and Co, A/S, Oslo, Norway) centrifugal sedimentation. ${ }^{35}$ A population of cells containing $98 \%$ lymphocytes was obtained. Possible contamination by monocytes was tested by staining with $\alpha$-naphthol acetate esterase. ${ }^{36}$ The isolated lymphocytes were washed twice, resuspended in phosphate buffered saline to a concentration of $2 \times 10^{6}$ cells $/ \mathrm{ml}$, and immediately used for fluorescence measurements.

\section{FLUORESCENCE LABELLING OF}

\section{LYM PHOCYTES}

1,6-Diphenyl-1,3,5-hexatriene was used as the fluorescent probe for monitoring the degree of fluidity of the cell membrane. DPH was dissolved in tetrahydrofuran at a concentration of $2 \times 10^{-3} \mathrm{~mol} / \mathrm{l}$. For cell labelling, the solution of DPH was diluted 1000 -fold by injection into vigorously stirred phosphate buffered saline. The dispersion of DPH obtained $\left(2 \times 10^{-6} \mathrm{~mol} / \mathrm{l}\right)$ was clear and practically lacking in fluorescence. One millilitre of this fluorescent probe solution was added to $1 \mathrm{ml}$ of cellular suspension $\left(2 \times 10^{6} \mathrm{cells} / \mathrm{ml}\right)$ to give a final probe concentration of $10^{-6} \mathrm{~mol} / 1 .{ }^{27} 28$

The incorporation of DPH into lymphocyte membranes was followed by a steep increase in fluor- escence intensity. With our experimental conditions we did not observe significant changes in spectral characteristics and kinetic incorporations of DPH into lymphocyte membranes of patients with RA in comparison with control membranes. After 45 minutes' incubation at room temperature the labelled cells were used for fluorescence studies.

FLUORESCENCE POLARISATION ANALYSIS DPH fluorescence polarisation was measured with a Perkin Elmer spectrofluorimeter MPF 44A. The excitation and emission wavelengths were respectively $365 \mathrm{~nm}$ and $430 \mathrm{~nm}$. The degree of DPH fluorescence polarisation (P) was obtained by the following equation:

$$
P=\frac{I_{\|}-I_{\perp} g}{I_{11}+I_{\perp} g}
$$

where $g$ is an instrumental correction factor, $I_{\|}$and $I_{\perp}$ are respectively the emission intensities polarised vertically and horizontally to the direction of the polarised light. For DPH the fluorescence polarisation values depend on probe rotational mobility and on the degree of order of membrane molecules; changes in fluorescence polarisation values have been correlated with changes in membrane microviscosity. In general, an increase of fluorescence polarisation indicates an increase of microviscosity and therefore a decrease of fluidity, assuming, on physical grounds, that fluidity is the reciprocal of viscosity. ${ }^{21}$

\section{STATISTICAL METHODS}

All results are expressed as mean (SD). Data were analysed by Student's $t$ test and the Mann-Whitney $\mathrm{U}$ test, and linear regression analysis was used for the calculation of correlation coefficients.

\section{Results}

Fig. 1 shows the individual values of DPH fluorescence polarisation in lymphocytes from healthy controls and patients with RA. Of the 27 patients with RA studied, 16 showed polarisation values clearly above the range of the controls, while the remaining cases were above the control mean value. Among the patients with RA there was a significant increase of DPH polarisation (Table 1) $(p<0.01$ Mann-Whitney test), indicating a decreased lymphocyte membrane fluidity. The applicability of this molecular approach in the study of RA pathogenetic mechanisms is confirmed by the lack of variability of polarisation values in relation to the sex and the age of the subjects. There were no significant differences in the mean polarisation values in relation to the sex and age either in the controls or in the 
patients with RA (Tables 1 and 2). In healthy women and men we obtained mean (SD) fluorescence polarisation values of $0.215(0.004)$ and $0 \cdot 218(0 \cdot 006)$ respectively. These values were

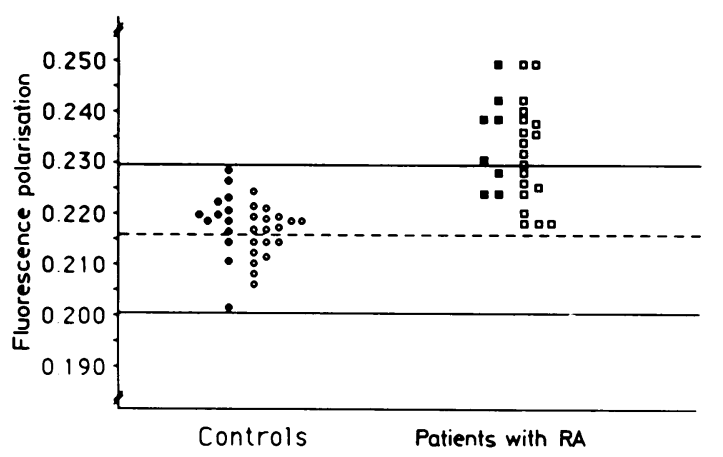

$\because$ men $\because$ women

Fig. 1 Fluorescence polarisation values of 1,6-diphenyl1,3,5-hexatriene in lymphocyte membranes of patients with rheumatoid arthritis $(\square, \square)$ and of control subjects $(\bullet, \bigcirc)$. The dashed line indicates the control mean fluorescence polarisation value, and the continuous lines the range of values for the controls.

Table 1 DPH fluorescence polarisation values related to sex of the subjects in lymphocytes from controls and patients with rheumatoid arthritis

\begin{tabular}{|c|c|c|c|c|}
\hline & \multicolumn{2}{|l|}{ Controls } & \multirow{2}{*}{\multicolumn{2}{|c|}{$\begin{array}{l}\text { Patients with } \\
\text { rheumatoid arthritis }\end{array}$}} \\
\hline & \multirow{2}{*}{$\begin{array}{l}\text { Fluorescence } \\
\text { polarisation } \\
\text { valuest }\end{array}$} & \multirow{2}{*}{ Number } & & \\
\hline & & & $\begin{array}{l}\text { Fluorescence } \\
\text { polarisation } \\
\text { values }{ }^{\dagger}\end{array}$ & Number \\
\hline Men & $0.218(0 \cdot(0) 6)$ & 1.3 & $0.235(0.008)^{*}$ & 8 \\
\hline Women & $0.215(0.0(04)$ & 19 & $0.232(0.009)^{*}$ & 19 \\
\hline Total & $0.217(0.005)$ & 32 & $0.233(0.009)^{*}$ & 27 \\
\hline
\end{tabular}

${ }^{*} \mathrm{p}<0.01$ Mann-Whitney test.

†Values are mean (SD). significantly different from those in women and men? with RA $(0.232(0.009)$ and $0.235(0.008)$ respec $\overrightarrow{\overrightarrow{\vec{\omega}}}$ tively; $p<0.01$ Mann-Whitney test) (Table 1). These results indicate an average increase of membrane등 fluorescence polarisation of $7-8 \%$ in the RA lymphocytes as compared with normal lymphocytes $\vec{\Phi}$ Although this difference between groups appears to be small in absolute value, the standard deviation of DPH fluorescence polarisation measurements is $\overrightarrow{0}$ extremely small so that the difference in the mean values for the two groups is highly significant $(\mathrm{p}<0 \cdot 01)$. To determine possible differences ine membrane fluidity in cells other than lymphocytes the fluidity of erythrocyte membrane isolated from patients with RA and from healthy controls was tested by fluorescence polarisation. No difference was detected in fluidity of erythrocyte membraneso from patients with RA and from control subjects (data not shown). When $0 \cdot 229$ was taken as the fluorescence polarisation cut off point, this being the upper limit of lymphocyte membrane fluidity in the normals (Fig. 1), the patients with RA were divideco into two classes, one having fluorescence polarisa $-\infty$ tion values lower than 0.229 and the other having values higher than $0 \cdot 229$. The patients with de-s creased lymphocyte membrane fluidity had the

Table 3 Comparison of disease activity indices and DPH fluorescence polarisation values $(P)$ in lymphocytes of patients with rheumatoid arthritis

\begin{tabular}{|c|c|c|}
\hline & $P<0.229$ & $P>0.229$ \\
\hline $\operatorname{ESR}(\mathrm{mm} / \mathrm{h})$ & $51(19) \div$ & $71(30)^{*}$ \\
\hline Fibrinogen $(\mathrm{g} / \mathrm{l})$ & $3.68(0.65)$ & $6 \cdot 16(1.34)^{*}$ \\
\hline$\alpha_{2}$ Globulins (g/l) & $0.78(0.07)$ & $0.79(0.07)$ \\
\hline Platelet count $\left(\times 10^{4} / 1\right)$ & $300(70)$ & $313(101)$ \\
\hline \multirow[t]{2}{*}{ Plasma viscosity $(\mathrm{cP}): 37^{\circ} \mathrm{C}$} & $1 \cdot 38(0 \cdot 16)$ & $1 \cdot 48(0 \cdot 12)$ \\
\hline & $2 \cdot 11(0 \cdot 21)$ & $2 \cdot 24(0 \cdot 17)$ \\
\hline C reactive protein $(\mathrm{mg} / \mathrm{l})$ & $28(18)$ & $34(12)$ \\
\hline Plasma sulphydryl groups ( $\mathrm{mg} / \mathrm{l}$ ) & $13 \cdot 7(1.5)$ & $13 \cdot 1((0 \cdot 9)$ \\
\hline Ritchic index & $17 \cdot 6(9)$ & $20(17)$ \\
\hline
\end{tabular}

Table 2 DPH fluorescence polarisation values related to age in lymphocytes from controls and patients with rheumatoid arthritis

\begin{tabular}{|c|c|c|c|c|}
\hline \multirow[t]{2}{*}{ Subjects } & \multicolumn{4}{|l|}{ Age (years) } \\
\hline & $20-35$ & $35-50$ & $50-65$ & $65-80$ \\
\hline Controls & $\begin{array}{l}0 \cdot 215(0 \cdot 010) \dagger \\
(n=12)\end{array}$ & $\begin{array}{l}0 \cdot 217(0 \cdot 004) \\
(n=8)\end{array}$ & $\begin{array}{l}0 \cdot 218(0 \cdot(004) \\
(n=6)\end{array}$ & $\begin{array}{l}0 \cdot 218(0 \cdot 007) \\
(n=6)\end{array}$ \\
\hline Patients with rheumatoid arthritis & $\begin{array}{l}0 \cdot 228(0 \cdot 010)^{*} \\
(n=6)\end{array}$ & $\begin{array}{l}0 \cdot 231(0 \cdot 007)^{* *} \\
(n=5)\end{array}$ & $\begin{array}{l}0 \cdot 231(0 \cdot 009)^{* * *} \\
(n=8)\end{array}$ & $\begin{array}{l}0 \cdot 237(0 \cdot 012)^{* * * *} \\
(\mathrm{n}=8)\end{array}$ \\
\hline
\end{tabular}

${ }^{*} \mathrm{p}=0 \cdot 008,{ }^{* *} \mathrm{p}=0 \cdot 001,{ }^{* * *} \mathrm{p}=0 \cdot 005,{ }^{* * * *} \mathrm{p}=0 \cdot 016$ as compared with controls

†Data are presented as mean (SD). 
highest ESR, CRP concentrations, Ritchie index, and plasma fibrinogen concentrations, whereas the patients with the lowest ESR, CRP concentrations, Ritchie index, and plasma fibrinogen concentrations had lymphocyte membrane fluidity in the normal range (Table 3). There were no differences in $\alpha_{2}$ globulin concentrations, platelet count, plasma sulphydryl groups, and plasma viscosity in the two groups. Moreover, both ESR and plasma fibrinogen concentrations were positively correlated with lymphocyte fluorescence polarisation measurements $(r=0.66, p<0.01 ; r=0.76, p<0.01$ respectively (Figs 2 and 3$)$.

\section{Discussion}

Using fluorescence polarisation, we have shown a decrease of fluidity in lymphocytes from patients with RA. Although apparently slight (average increase $7-8 \%$ ), the observed changes in membrane physical state are noteworthy as much experimental evidence has shown that even small modifications of fluidity can affect membrane functions through the control exerted by phospholipid matrix on membrane protein activities. Moreover, changes similar to those found by us have been reported in cell membranes either in experimental or in human disease. ${ }^{24} 37-39$

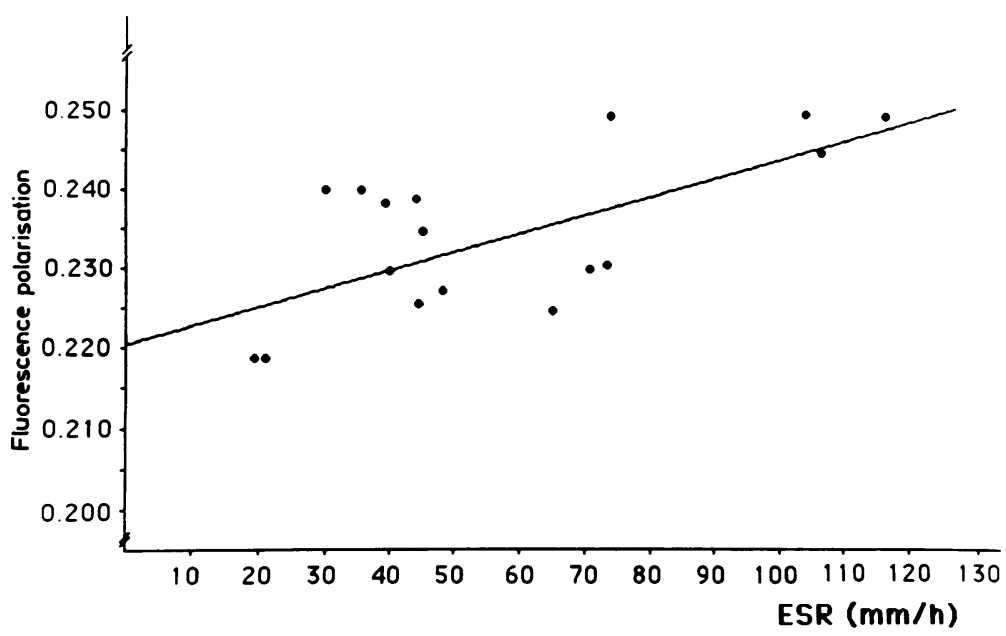

Fig. 2 Correlation between erythrocyte sedimentation rate $(E S R)$ and fluorescence polarisation of 1,6-diphenyl-1,3,5hexatriene in lymphocyte membranes from patients with rheumatoid arthritis $(r=0 \cdot 66$, $p<0 \cdot 01)$.

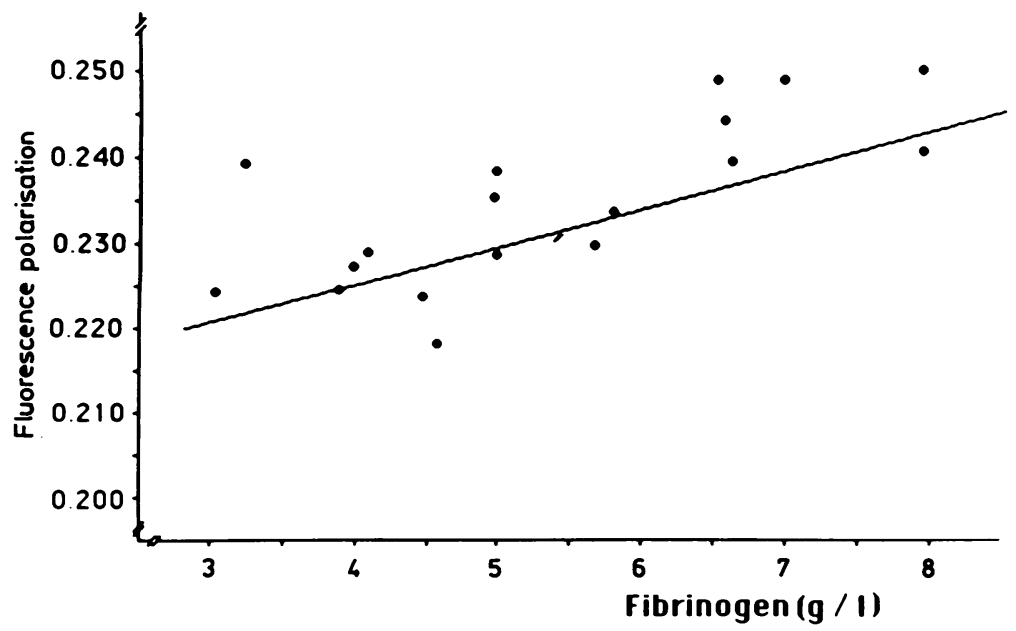

Fig. 3 Correlation between plasma fibrinogen concentrations and fluorescence polarisation of 1,6-diphenyl-1,3,5-hexatriene in lymphocyte membranes from patients with rheumatoid arthritis $(r=0.76, p<0.01)$. 
The study of cell membrane fluidity in various human diseases has received increasing attention in recent years and it has been used to investigate disease at the molecular level. The alterations we observed in lymphocyte membrane can be considered specifically linked to this cell as non-specific effects can be excluded by the finding that erythrocyte membrane fluidity was not modified. Further relevance to these results comes from the association of the highest polarisation values with the highest Ritchie index and CRP concentrations; fluorescence polarisation values were also positively correlated with ESR and plasma fibrinogen concentrations. As ESR and plasma fibrinogen concentrations are considered to be indicators of disease activity our results suggest that alterations in lymphocyte membrane fluidity could be related to inflammation; it is not possible to explain at present, however, why positive correlations have been found for only two indices and not for all the indices studied.

A hypothesis can be advanced about the molecular mechanisms involved in the changes of membrane physical state shown in RA lymphocytes. The membrane fluidity is related to the structural organisation of phospholipid molecules, in particular in the membrane hydrophobic core probed by DPH; a decrease of acyl chain unsaturation produces a decrease of fluidity. After the respiratory burst the release of free radicals and active oxygen species causes damage to membrane proteins ${ }^{40}$ and induces the peroxidation of polyunsaturated fatty acids of membrane phospolipids. ${ }^{41} 42$ In phospholipid liposomes lipid peroxidation has been shown to increase membrane rigidity. ${ }^{43}$ This effect could be of importance in lymphocyte membranes, which have a high content of unsaturated fatty acid and a very high susceptibility to lipid peroxidation. Moreover, in RA there is evidence of increased levels of free radical oxidation products in serum and synovial fluid $^{44} 45$ and evidence of decreased levels of free radical scavengers and antioxidant enzyme systems, which normally protect the biological membranes from peroxidation. The increase of lipid peroxidation or the decrease of antioxidant systems could induce the observed changes in lymphocyte membrane fluidity, and these could be either a passive consequence of the disease condition or be directly involved in its pathogenetic mechanism. Although further studies are necessary to elucidate these aspects of membrane damage, we suggest that the lymphocyte membrane can be used to investigate molecular events of RA.

The authors are grateful to Professor Claudio Cervini for his helpful comments in the preparation of the manuscript.

\section{References}

1 Gale R, Bertouch J V. Gordon T P, Bradley J, Roberts Thompson P J. Neutrophil activation by immune complexes and the role of rheumatoid factor. Ann Rheum Dis 1984; 43: 34-9등

2 King S L, Parker J, Cooper R, Sturrock R, Gemmel C G Polymorphonuclear leucocyte function in rheumatoid arthritis Br J Rheumatol 1986; 25: 26-33.

3 Van Boxel J A, Paget S A. Predominantly T-cell infiltrate in rheumatoid membranes. $N$ Engl J Med 1975; 293: 517-20.

4 Cervini C, Numo R. Artrite reumatoide. In: Introzzi P, ed Trattato Italiano di medicina interna. Part 10. Florence: USES 1983: 233-320.

5 Wooley P H, Panayi G S. Studies of lymphocytes in rheumatoi arthritis. Ann Rheum Dis 1978; 37: 343-6.

6 Waldmann T A, Broder S. Polyclonal B-cell activators in the study of the regulation of immunoglobulin synthesis in the human system. Adv Immunol 1982; 32: 1-25.

7 Zanders E. Lymphocyte receptors and transmembrane signal ling. In: Cohen P, Houslay M D, eds. Molecular mechanisms of transmembrane signalling Amsterdam: Elsevier, 1985: 411-27

8 Weigandt $\mathrm{H}$. Hormone reception and the cell surface-a응 overview. In: Bertoli E, Chapman D, Cambia A, Scapagnini Uب eds. Biomembrane and receptor mechanism. Padova: Liviang Press, 1987: 269-77.

9 Pearson C M, Paulus H E, Mackleder H. The role of th lymphocyte and its products in the propagation of joint disease $\overrightarrow{C O}$ Ann NY Acad Sci 1975; 256: 150-68.

10 Paulus H E, Machleder H I, Levine S, Yu D T Y, MacDonald N S. Lymphocyte involvement in rheumatoid arthritis: in longitudinal thoracic duct drainage. Arthritis Rheum 1977; 209 1249-62.

11 Karsh J, Klippel J M, Plotz P H, Decker J L, Wright D G, Fly $\mathrm{M}$ W. Lymphapheresis in rheumatoid arthritis: a randomize trial. Arthritis Rheum 1981; 24: 867-73.

12 De Vries E, Van Buijsen A C, Van Der Weij J P, Haasnoo C J P, Meijer C J L M, Cats A. Morphometric analysis oథ peripheral blood and synovial fluid lymphocytes of patients witß rheumatic disease. J Rheumatol 1983; 10: 12-18.

13 Corrigal V, Panayi G S, Laurent R. Lymphocyte studies i⿱ rheumatoid arthritis. Scand J Rheumatol 1979; 8: 10-16.

14 Papadimitrou G M, Bacon P A, Hall N D. Circulating activate lymphocytes in rheumatoid arthritis: a marker of synovial inflammation. $J$ Rheumatol 1982; 9: 217-23.

15 Froebel K S, Lewis D, Dickson R, Sturrock R D. Spontaneoư⿱ lymphocyte activity in rheumatoid arthritis in a longitudina study in relation to gold therapy. Clin Rheumatol 1985; 48 301-7.

16 Loor F. Cell surface-cell cortex transmembranous interaction? with special reference to lymphocyte functions. In: Poste GP Nicholson G L, eds. Cytoskeletal elements and plasma mem brane organization. Vol 6. Amsterdam: North Holland 1981 253-335.

17 Roozemond R C, Bonavida B. Effect of altered membran fluidity on NK cell-mediated cytotoxicity. J Immunol 1985; 1340 2209-14.

18 Lenaz G, Curatola G, Fiorini R M, Parenti Castelli $G_{\odot}$ Membrane fluidity and its role in the regulation of cellular processes. Biology of Cancer 1983; 2: 25-34.

19 Edidin M. Rotational and translational diffusion in membranes Annual Reviews of Biophysics and Bioengineering 1974; $3 ?$ 179-201.

20 Borochov H, Shinitzky M. Vertical displacement of membranब proteins mediated by changes in microviscosity. Proc Natl Acaळ Sci USA 1976; 73: 4526-30.

21 Shinitzky $M$. Membrane fluidity and cellular functions. In Shinitzky M, ed. Physiology of membrane fluidity. Boca Ratong Florida: CRC Press, 1984; 1-52.

22 Cooper R A. Abnormality of cell membrane fluidity in the pathogenesis of disease. $N$ Engl J Med 1977; 197: 371-7.

\section{年}


23 Curatola G, Ferretti G, Bertoli E, Dotti M. Bartolotta E, Giorgi P L. Changes of membrane fluidity in erythrocytes of obese children: a spin label study. Pediatr Res 1987; 22: 141-4.

24 Inbar M, Goldman R, Inbar I, et al. Fluidity differences of membrane lipids in human and leukemic lymphocytes as controlled by serum components. Cancer Res 1977; 37: 3037-41.

25 Benedetti A. Birarelli A M, Brunelli E, et al. Effect of chronic ethanol abuse on the physico-chemical properties of erythrocyte membranes in man. Pharmacol Res Commun 1986; 18: 1003-14.

26 Baba Y, Kai M, Kamadett T, Setayama S, Otsuji S. Higher levels of erythrocyte membrane microviscosity in diabetes. Diabetes 1979; 28: 1138-40.

27 Shinitzky M, Inbar M. Difference in microviscosity induced by different cholesterol levels in the surface membrane lipid layer of normal lymphocytes and malignant lymphoma cells. $J \mathrm{Mol}$ Biol 1974; 85: 603-15.

28 Shinitzky M, Barenholz Y. Fluidity parameters of lipid regions determined by fluorescence polarization. Biochim Biophys Acta 1978; 515: 367-94.

29 Westergren A. The technique of the red cell sedimentation reaction. American Review of Tuberculosis 1926; 14: 94-101.

30 Kohn J. Cellular acetate electrophoresis. In: Smith I, ed. Chromatographic and electrophoretic techniques. Vol 2. London: Heinemann, 1968: 84-9.

31 Singer J M, Plotz C M, Elster S K. The latex fixation test. III. Agglutination test for $\mathrm{C}$ reactive protein and comparison with the capillary precipitin method. Am J Clin Pathol 1957; 28: 611-7.

32 Mancini G, Carbonara A O, Heremans J F. Immunochemical quantitation of antigens by single radioimmunodiffusion. $\mathrm{Im}$ munochemistry 1965; 2: 235-8.

33 Simplicio P. An improved method of determination of SH group concentration and reactivity in plasma of patients with various clinical disorders and in rats after administration of indomethacin or carbon tetrachloride. Pharmacol Res Commun 1983; 15: 805-14.

34 Harkness J. The viscosity of human blood plasma-its measurement in health and disease. Biorheology 1971; 8: 171-93.

35 Spiegelberg H, Dainer P. Fc receptors for IgG, IgM and IgE on human leukemic lymphocytes. Clin Exp Immunol 1979; 35: 286-95.

36 Fox R I, Thompson L F, Huddlestone J R. Ty cells express Tcell associated antigens. J Immunol 1981; 126: 2062-3.

37 Ferretti G, Falcioni A M, Curatola G, Valentini B, Saccucci F. Duchenne muscular dystrophy: alterations in lymphocyte fluidity. Boll Soc Ital Biol Sper 1983; 59: 1035-40.

38 Zubenko G S, Cohen B M, Growdon J, Corkin S. Cell membrane abnormality in Alzheimer's disease. Lancet 1984; ii: 235.

39 Inbar M, Yuli I, Raz A. Contact-mediated changes in the fluidity of membrane lipids in normal and malignant transformed mammalian fibroblast. Exp Cell Res 1977; 105: 325-35.

40 Fantone J C, Ward P A. Polymorphonuclear leukocytemediated cell and tissue injury: oxygen metabolites and their relations to human disease. Hum Pathol 1985; 16: 973-8.

41 Clavel J P, Emerit J, Thuillier A. Lipidoperoxydation et radicaux libres. Pathol Biol (Paris) 1985; 33: 61-9.

42 Stossel T P, Mason R J, Smith A L. Lipid peroxidation by human blood phagocytes. J Clin Invest 1974; 54: 638-45.

43 Dobretsov G E, Borschevskaya T A, Petrov V A, Vladimirov Y A. The increase of phospholipid bilayer rigidity after lipid peroxidation. FEBS Lett 1977; 84: 125-8.

44 Lunec J, Halloran S P, White A G, Dormandy T L. Freeradical oxidation (peroxidation) products in serum and synovial fluid in rheumatoid arthritis. J Rheumatol 1981; 8: 233-45.

45 Gutteridge J M C, Hill C, Blake D R. Copper stimulated phospholipid membrane peroxidation: antioxidant activity of serum and synovial fluid from patients with rheumatoid arthritis. Clin Chim Acta 1984; 139: 85-90. 